\title{
Propiedades químicas, físicas y biológicas del suelo, indicadores del estado de diferentes ecosistemas en una terraza alta del departamento del Meta
}

\author{
Chemical, physical and biological soil properties, indicators of the \\ status of different ecosystem in a high terrace of the Meta department
}

\author{
Propriedades químicas, físicas e biológicas do solo, indicadores \\ do estado de diferentes ecossistemas em um alto terraço do \\ departamento meta
}

Claudia L Calderón-Medina1 , Gina P Bautista-Mantilla², Salvador Rojas-González ${ }^{3}$



Recibido: 22 de noviembre de $2017 \quad$ Aceptado: 19 de noviembre de 2018

\begin{abstract}
Resumen
Con el propósito de avanzar en la valoración de las propiedades químicas, físicas y biológicas como indicadores de calidad del suelo en un sistema agroforestal, se evaluaron tres sistemas de uso en suelos de terraza alta ubicados en el C.I La Libertad de Agrosavia: bosque, sistema agroforestal (SAF) y pradera. Se tomaron muestras de suelo a dos profundidades 0-10 cm (P1) y 10-20 cm (P2). Se midieron variables químicas y físicas, se hizo recuento microbiano de hongos, bacterias, actinomicetos y mesoinvertebrados, estos se identificaron a nivel de familia y especie. Inicialmente, se realizó análisis descriptivo de los datos y se interpretaron de acuerdo con los valores de referencia reportados. El análisis estadístico se realizó por medio de Análisis de Componentes Principales (ACP), análisis de varianza y prueba de comparación de medias de Duncan (para lo cual se utilizaron los software estadísticos R versión 3.1.2 (paquete ADE4 1.4.5) e INFOSTAT 2014I). Se seleccionaron las variables químicas $\mathrm{pH}$, aluminio intercambiable $(\mathrm{AlH})$, fósforo $(\mathrm{P})$, calcio $(\mathrm{Ca})$, magnesio $(\mathrm{Mg})$, potasio $(\mathrm{K})$, boro $(\mathrm{B})$, azufre $(\mathrm{S})$, sodio $(\mathrm{Na})$, zinc $(\mathrm{Zn})$, capacidad de intercambio catiónico efectiva $(\mathrm{CICE})$ y las variables fisicas conductividad hidráulica $(\mathrm{CH})$, densidad aparente (DA), mesoporosidad (MES), porosidad total (PT), saturación (SAT), capacidad de campo (CC), humedad disponible (HD), microporosidad (MIC), punto de marchitez permanente (PMP), porcentaje de arena y arcilla, que permiten separar los sistemas en cuanto a la calidad del suelo. En el SAF se encontró moderada calidad química representada por altos valores de $\mathrm{pH}(5,30)$, bajo $\mathrm{AlH}(1,02 \mathrm{Cmol} / \mathrm{kg})$, bajos contenidos de Ca en $\mathrm{P} 1$ (1,49 $\mathrm{Cmol} / \mathrm{kg})$ y $\mathrm{P} 2(0,71 \mathrm{Cmol} / \mathrm{kg})$, bajo $\mathrm{Mg}$ en $\mathrm{P} 1(0,49 \mathrm{Cmol} / \mathrm{kg})$ y $\mathrm{P} 2(0,21 \mathrm{Cmol} / \mathrm{kg})$ y, los mayores valores encontrados de $\mathrm{S}(13,08 \mathrm{mg} / \mathrm{kg})$ y $\mathrm{Zn}(0,70 \mathrm{mg} / \mathrm{kg})$ en P2. A su vez, el SAF mostró baja calidad física con valores de DA de 1,34 g/cm3 en $\mathrm{P} 1$ y $1,46 \mathrm{~g} / \mathrm{cm} 3$ en P2. Las variables biológicas no contribuyeron a la diferenciación entre sistemas, sin embargo, el bosque
\end{abstract}


arrojó un mayor número de actinomicetos y hongos micorrizicos arbusculares (HMA) asociados a una mayor asimilación de nutrientes como el P.

Palabras clave: Sistema agroforestal; SAF; bosque; pradera; indicador.

\begin{abstract}
In the evaluation of the chemical, physical and biological properties as soil quality indicators for agroforestry systems, three systems of land use were valued. These systems are located in high terrace soils in the La Libertad de Agrosavia were evaluated: forest, system agroforestry (SAF) and grassland. Soil samples were taken at two depths 0-10 cm (P1) and 10-20 cm (P2). Chemical and physical variables were measured, microbial counts were made of fungi, bacteria, actinomycetes and mesoinvertebrates. These organism were identified at family and species level. Initially, a descriptive analysis of the data was performed and interpreted according to the reported reference values. The statistical analysis was carried out through Principal Component Analysis (PCA), variance analysis and Duncan's mean comparison test (for which statistical software $\mathrm{R}$ version 3.1.2 (package ADE4 1.4.5) and INFOSTAT were used. 2014I). Chemical variables were selected: $\mathrm{pH}$, exchangeable aluminum $(\mathrm{AlH})$, phosphorus $(\mathrm{P})$, calcium $(\mathrm{Ca})$, magnesium $(\mathrm{Mg})$, potassium $(\mathrm{K})$, boron $(\mathrm{B})$, sulfur $(\mathrm{S})$, sodium $(\mathrm{Na})$, zinc $(\mathrm{Zn})$, effective cation exchange capacity (CICE) and the physical variables hydraulic conductivity $(\mathrm{CH})$, bulk density (DA), mesoporosity (MES), total porosity (PT), saturation (SAT), field capacity (CC), available humidity (HD), microporosity (MIC), permanent wilting point (PMP), percentage of sand and clay, which allow to separate the systems in terms of soil quality. In the SAF, moderate chemical quality was found, represented by high pH values (5.30), low AlH (1.02 Cmol / kg), low contents of $\mathrm{Ca}$ in P1 $(1.49 \mathrm{Cmol} / \mathrm{kg})$ and P2 $(0,71 \mathrm{Cmol} / \mathrm{kg})$, under $\mathrm{Mg}$ in P1 $(0.49 \mathrm{Cmol} / \mathrm{kg})$ and P2 $(0.21 \mathrm{Cmol}$ $/ \mathrm{kg}$ ) and, the highest values found of S $(13.08 \mathrm{mg} / \mathrm{kg})$ and $\mathrm{Zn}(0.70 \mathrm{mg} / \mathrm{kg})$ in P2. In turn, the SAF showed low physical quality with DA values of $1.34 \mathrm{~g} / \mathrm{cm} 3$ in P1 and $1.46 \mathrm{~g} / \mathrm{cm} 3$ in P2. The biological variables did not contribute to the differentiation between systems, however, the forest showed a greater number of actinomycetes and arbuscular mycorrhizal fungi (AMF) associated with greater assimilation of nutrients such as $\mathrm{P}$
\end{abstract}

Key words: Agroforestry system; SAF; forest; grassland; indicator.

\title{
Resumo
}

Com o objetivo de avançar na avaliação das propriedades quimicas, físicas e biológicas como indicadores de qualidade do solo em um sistema agroflorestal, foram avaliados os siguientes sistemas de uso do solo no Cl La Libertad de Agrosavia: Floresta, Sistema agroflorestal (SAF) e Praderia. As amostras de solo foram coletadas em duas profundidades de 0-10 cm (P1) e 10-20 cm (P2). Variáveis químicas e físicas, micróbios de fungos, bactérias, actinomicetos e mesoinvertebrados foram identificados, estes foram identificados em nível de família e espécie. Inicialmente, foi realizada uma análise descritiva dos dados e a concordância foi interpretada com os valores de referência reportados. A análise estatística foi realizada no meio da análise dos componentes principais (PCA), a análise da variância e o teste de comparação dos meios de Duncan (para o qual é utilizado o software estatístico R versão 3.1.2 ( pacote ADE4 1.4.5) e INFOSTAT 2014I). química variáveis de $\mathrm{pH}$, permutável alumínio $(\mathrm{AlH})$, fósforo $(\mathrm{P})$, cálcio $(\mathrm{Ca})$, magnésio $(\mathrm{Mg})$, potássio $(\mathrm{K})$, boro $(\mathrm{B})$, enxofre $(\mathrm{S})$, sódio $(\mathrm{Na})$, foram seleccionados zinco ( Zn), capacidade de permuta catiónica eficaz (ICC) e da condutividade hidráulica variável (CH), a densidade a granel (BD), mesoporosidade (MES), a porosidade total (PT), a saturação (SAT), a capacidade de campo (CC), humidade disponível (HD), microporosidade (MIC), ponto de execução permanente (PMP), porcentagem de areia e argila, que permite separar os sistemas em termos de qualidade do solo. No SAF há uma qualidade química moderada representada por altos valores de $\mathrm{pH}(5,30)$, baixo $\mathrm{AlH}(1,02 \mathrm{Cmol} / \mathrm{kg})$, baixos teores de Ca em P1 $(1,49 \mathrm{Cmol} / \mathrm{kg})$ e P2 $(0,71 \mathrm{Cmol} / \mathrm{kg})$, sob Mg em P1 (0,49 Cmol / kg) e P2 (0,21 Cmol / kg), os maiores valores encontrados de S (13,08 mg / kg) e Zn (0,70 mg / kg) em P2. Por sua vez, o SAF apresentou uma qualidade física com valores de DA de 1,34 g / cm3 em P1 e 1,46 g / cm3 em P2. As variáveis biológicas não contribuem para a diferenciação entre os sistemas, no entanto, os solos da floresta mostraram um maior número de actinomicetos e fungos micorriza arbusculares (HMA) associada a uma maior absorção de nutrientes, tais como P.

Palavras-chave: Sistema agroflorestal; SAF; floresta; pradería; indicador.

\section{Introducción}

La franja localizada en la base de la cordillera oriental con alturas que oscilan entre los 200 y $700 \mathrm{~m}$ y que se extiende desde el municipio de Uribe hasta el río Upía abarcando hacia el oriente hasta los ríos Metica y Guayabero se conoce como Piedemonte. En este paisaje el relieve predominante son las terrazas, abanicos, lomas y colinas. Los suelos son ácidos, con contenidos de bases intercambiables medios a bajos, fosforo aprovechable bajo, saturación de aluminio de media a alta y capacidad de intercambio catiónico media; las zonas aluviales son más fértiles porque reciben materiales de las zonas altas y viejas del piedemonte; estructuralmente son frágiles, susceptibles a la erosión y compactación por el uso de implementos de labranza en el establecimiento de sistemas productivos. En parte de 
suelos cultivados se han formado capas endurecidas que limitan la movilidad del agua, impiden el intercambio gaseoso y por lo mismo afectan el establecimiento de diferentes especies de plantas. El uso continuo de arados y rastras invierte el perfil, disminuyen el tamaño de los agregados que quedan expuestos y ocasionan pérdidas por erosión y posterior degradación de la capacidad productiva del mismo (Amézquita y Chávez, 2000; IGAC, 2004; Rincón y Caicedo, 2010 y Gutierrez, 2011).

En consecuencia, la calidad del suelo se ve afectada por problemas como el aumento de la densidad aparente, la compactación y perdida por erosión que disminuyen la productividad de los sistemas, la ganadería se asocia con la degradación del ecosistema por el impacto que causa en el suelo y por la presión que ha ejercido sobre el bosque consecuencia de la tala de árboles para el establecimiento de pasturas.

El estado del suelo en cuanto a la función determina la calidad del mismo para determinado uso y por tanto el comportamiento del sistema de producción en él establecido. En este sentido, es necesario medir el impacto de los tipos de uso sobre la calidad del suelo para lo cual se deben establecer indicadores.

"Un indicador es una variable que resume o simplifica información relevante haciendo que un fenómeno o condición de interés se haga perceptible y que cuantifica, mide y comunica, en forma comprensible, información relevante" (Cantú et al., 2007); el resultado de valorar las características químicas y físicas del suelo en un periodo de tiempo y lugar específico es un insumo para la construcción de indicadores de calidad.

En este sentido, las propiedades químicas se relacionan con la calidad y disponibilidad de agua y nutrimentos para las plantas, entre ellas, cabe resaltar: $\mathrm{pH}$, materia orgánica, conductividad eléctrica y $\mathrm{P}, \mathrm{N}$ y, K extractables; de la misma forma, las características físicas reflejan la manera como el suelo almacena y provee agua a las plantas $y$, permite el desarrollo radical, entre ellas se encuentran propiedades como: estructura, densidad aparente, estabilidad de agregados, infiltración, profundidad conductividad hidráulica y capacidad de almacenamiento (Bautista et al., 2004).

Por otra parte la biología del suelo es amplia compleja y dinámica, la meso y macrobiota del suelo desempeñan un papel fundamental en la fragmentación, transformación y translocación de materiales orgánicos en él, además, aportan considerables cantidades de biomasa al suelo y mejoran algunas de sus propiedades físicas. El muestreo de mesofauna se considera parte importante del inventario de biodiversidad del suelo. (Karyanto, 2012). Colémbolos y ácaros son considerados transformadores de hojarasca y microdepredadores de otros organismos, contribuyen en procesos de trituración a pequeña escala y son importantes reguladores de la biota del suelo. Dentro de la macrofauna se encuentran termitas y lombrices de tierra que se conocen como ingenieros del ecosistema ya que causan impacto físico en el suelo mediante su transporte, construcción de estructuras agregadas y formación de poros; al cavar sus túneles y mediante la ingestión de material mineral y orgánico afectan la porosidad y además actúan como reguladores de microfauna; cochinillas, milpiés y larvas de insectos actúan como transformadores de hojarasca ejerciendo su acción trituradora sobre el tejido de plantas muertas y sus depredadores (ciempiés, arácnidos grandes y otros tipos de insectos) (Swift et al., 2012).

Los hongos presentes en el suelo son esenciales en los procesos de ciclaje de nutrientes, interactúan con actinomicetos bacterias y mesorganismos y son mediadores entre patógenos y antagonistas manteniendo el equilibrio del sistema, mejoran la disponibilidad de nutrientes y tolerancia al estrés abiótico (Pfenning y Magalhães de Abreu, 2012) Los hongos micorrizógenos arbusculares (HMA) mejoran la salud del suelo, lo cual se refleja en el crecimiento y desarrollo de las plantas, ya sea en sistemas agrícolas, hortícolas o forestales (Bagyaraj y Sturmer, 2012)

Existen diferentes maneras de conocer la biodiversidad que alberga un sistema, entre ellos, el índice de Simpson que indica la probabilidad de que dos individuos sacados al azar de una muestra pertenezcan a la misma especie, está fuertemente influenciado por la importancia de las especies más dominantes. El Índice de Shannon-Wiener el cual asume que todas las especies están representadas en las muestras e indica que tan uniforme están las especies en abundancia respecto a todas las especies muestreadas y los índices de similitud/disimilitud como el Coeficiente de Jaccard que determinan el grado en que los sistemas son semejantes en relación a las especies que los habitan (Moreno, 2001; Villareal et al., 2004; Martella et al., 2012).

Agrosavia ha investigado la introducción de árboles multipropósito en sistemas ganaderos para mejorar la productividad favoreciendo el ciclaje de nutrientes, producción de materia orgánica, protección física del suelo y diversidad de especies (Bueno, 2010). De igual manera, trabajó con especies transitorias asociadas a cultivos perennes en los primeros estadios de desarrollo y en 2011 avanzó en la construcción de 
indicadores a partir de la medición de variables fisicoquímicas, macrofauna, gases efecto invernadero (GEI) y contenido de carbono del suelo en sistemas productivos de la altillanura entre Puerto López y Carimagua (Rodríguez et al., 2012). Al mismo tiempo, se ha avanzado en el estudio de sistemas agroforestales como alternativa de uso del suelo para medianos y pequeños productores.

No obstante, se desconoce el impacto del sistemas agroforestales (SAF) sobre la condición del suelo y por lo mismo se desarrolló este trabajo con el objeto de avanzar en la valoración de las propiedades químicas, físicas y biológicas como indicadores de calidad del suelo en el SAF.

\section{Materiales y métodos}

El estudio se realizó en el Centro de Investigación La libertad de Agrosavia, ubicado a $336 \mathrm{msnm}$, latitud norte $4^{\circ} 03^{\prime}$ y longitud oeste $73^{\circ} 29^{\prime}$; con precipitación promedio anual de $2.918 \mathrm{~mm}$, temperatura media de $26{ }^{\circ} \mathrm{C}$, humedad relativa (HR) $80 \%$ y factor de humedad entre 201 y 300.

Se evaluaron tres sistemas de uso del suelo: sistema agroforestal (SAF), pradera y bosque. El SAF (2 ha) establecido en 2009, en surcos con especies frutales y forestales maderables y no maderables. La pradera (1 ha) establecida con Braquiaria decumbens sin fertilización química durante 7 años, con 2,5 animales por ha (de $300 \mathrm{~kg}$ ) en pastoreo, y periodos de descanso de 30 días. El Bosque (1,5 ha) con cobertura característica de bosque secundario y estructura semiabierta.

En el SAF se seleccionaron cuatro sitios ubicados en los surcos de las especies Acerola- Rambután, YopoHuito, Marañon- Camu camu, y Chontaduro- Arazá; en la pradera se ubicaron tres puntos al azar en triángulo teniendo en cuenta que ninguno de ellos estuviese cerca del límite del lote (ICA, 1992)

En el bosque se delimitaron tres parcelas de monitoreo de 50×20 m y dentro de cada una se ubicó un sitio de muestreo (metodología modificada Gutiérrez y Valderrama 2000, Salazar 2012 y ajustada de acuerdo con la forma y características del área de estudio.

En cada sitio se consideró un área de $1 \mathrm{~m}^{2}$ aproximadamente donde se realizó la toma de muestras de suelo para análisis químico y físico en época de lluvias (Abril de 2012) y época seca (Febrero de 2013), a dos profundidades que se identificaron así: para el análisis químico P1: 0-10 cm y P2: 10-40 cm, y para el análisis físico P1: 0-10 cm y P2: 10-20 cm
Para el análisis químico de suelos, se tomaron muestras de $500 \mathrm{~g}$ y se determinó el contenido de materia orgánica (M.O), fósforo $(\mathrm{P})$, $\mathrm{pH}$, calcio $(\mathrm{Ca})$, magnesio $(\mathrm{Mg})$, potasio $(\mathrm{K})$, sodio $(\mathrm{Na})$, acidez intercambiable $(\mathrm{AlH})$, hierro $(\mathrm{Fe})$, cobre $(\mathrm{Cu})$, manganeso $(\mathrm{Mn})$, Zinc $(\mathrm{Zn})$, Boro $(\mathrm{B})$, azufre $(\mathrm{S})$ y capacidad de intercambio catiónico efectiva (CICE)

Para el análisis físico, se tomaron muestras de suelo no disturbadas utilizando anillos de 3 por $2,5 \mathrm{~cm}$ de diámetro y se evalúo conductividad hidráulica $(\mathrm{CH})$, densidad aparente (DA), densidad real (DR), macroporosidad (MAC), mesoporosidad (MES), microporosidad (MIC), porosidad total (PT), saturación (SAT), capacidad de campo (CC), punto de marchitez permanente (PMP), humedad disponible (HD), contenido de arena (A), limo (L) y arcilla (Ar). Además se midió la resistencia a la penetración del suelo con Penetrógrafo EijkeIkamp. El método utilizado para determinar cada una de las variables químicas y físicas se relaciona en la tabla 1 y corresponden al Laboratorio de Química y Física de suelos de Agrosavia.

Para evaluar la biología del suelo se hizo conteo e identificación de hongos micorrizógenos, hongos, bacterias y actinomicetos (Noviembre de 2012) y también se identificó el orden y familia de mesoinvertebrados y la población de individuos (mayo de 2013).

Se tomaron 5 submuestras por sitio en los primeros 15 $\mathrm{cm}$ del perfil, con barreno de tornillo, las cuales formaron una muestra de 500 g, que se llevó al Laboratorio de Microbiología y Fitopatología de la Universidad de los Llanos para recuento poblacional microbiano (hongos, bacterias, actinomicetos) por el método de diluciones seriadas de Novo 1983, citado por, Roncallo, 2012). De igual manera, se recolectaron y llevaron muestras de 500 g para conteo de esporas e identificación de Hongos Formadores de Micorrizas Arbusculasres (HFMA), las cuales se tomaron en la zona del perímetro de la copa, la separación de las esporas extraídas se realizó por el método de Ohms (1957) modificado por Sieverding (1989) y para la identificación de los HFMA se utilizó la clave taxonómica de Shenck y Pérez, 1990. (Hernández 2005, Salamanca y Cano, 2005, Monroy et al., 2013). Por último, para estimar la mesofauna se recolectaron muestras con una cajuela de $10 \times 10 \times 10 \mathrm{~cm}$, se extrajeron los organismos por medio del método del Embudo de Berlese- Tullgren (Socarras y Robaina, 2011) y se identificaron a nivel de orden o familia con el apoyo de la unidad de entomología del C.I La Libertad.

Para identificar las variables químicas, físicas y biológicas se adiciono 1 para P1 y 2 para P2. 
Tabla 1. Métodos utilizados para determinar las variables químicas y fiscas del suelo

\begin{tabular}{|c|c|}
\hline Variable & Método utilizado \\
\hline \multicolumn{2}{|l|}{ Variables Químicas } \\
\hline $\mathrm{pH}$ & Potenciómetro \\
\hline $\mathrm{MO}(\%)$ & Walkey \& Black. Espectrometría molecular \\
\hline $\mathrm{P}(\mathrm{mg} / \mathrm{Kg})$ & Fósforo Total Bray II Determinación Colorimétrica \\
\hline $\mathrm{S}(\mathrm{mg} / \mathrm{Kg})$ & Azufre Extractable (Fosfato Ca) Turbidimetría. \\
\hline $\mathrm{Al}+\mathrm{H}(\mathrm{Cmol} / \mathrm{kg})$ & Aluminio Cambiable ( $\mathrm{KCl} 1 \mathrm{M})$ Volumetría \\
\hline $\mathrm{CE}((\mathrm{dS} / \mathrm{m}))$ & Conductividad Eléctrica NTC 5596 \\
\hline $\mathrm{Ca}(\mathrm{Cmol} / \mathrm{kg})$ & Calcio Intercambiable. Espectrometría de absorción atómica \\
\hline $\mathrm{Mg}(\mathrm{Cmol} / \mathrm{kg})$ & Magnesio Intercambiable. Espectrometría de absorción atómica \\
\hline $\mathrm{K}(\mathrm{Cmol} / \mathrm{kg})$ & Potasio Intercambiable. Espectrometría de absorción atómica \\
\hline $\mathrm{Na}(\mathrm{Cmol} / \mathrm{kg})$ & Sodio Intercambiable. Espectrometría de absorción atómica \\
\hline $\mathrm{Cu}(\mathrm{mg} / \mathrm{Kg})$ & Cobre Extract. Doble Acido Ab.At. Espectrometría de absorción atómica \\
\hline $\mathrm{Fe}(\mathrm{mg} / \mathrm{Kg})$ & Hierro Extract. Doble Acido Ab.At. Espectrometría de absorción atómica \\
\hline $\mathrm{Mn}(\mathrm{mg} / \mathrm{Kg})$ & Manganeso Extract. Doble Acido Ab.At. Espectrometría de absorción atómica \\
\hline $\mathrm{Zn}(\mathrm{mg} / \mathrm{Kg})$ & Zinc Extract. Doble Acido Ab.At. Espectrometría de absorción atómica \\
\hline $\mathrm{B}(\mathrm{mg} / \mathrm{Kg})$ & Boro. NTC 5404 \\
\hline \multicolumn{2}{|l|}{ Variables físicas } \\
\hline $\mathrm{CH}(\mathrm{cm} / \mathrm{h})$ & Permeámetro de carga constante \\
\hline Humedad & Gravimétrico y Volumétrico \\
\hline $\mathrm{Da}(\mathrm{g} / \mathrm{cm} 3)$ & Cilindro de Volumen conocido \\
\hline $\operatorname{Dr}(\mathrm{g} / \mathrm{cm} 3)$ & Picnómetro \\
\hline Curvas de retención & Olla de Presión \\
\hline Textura & Hidrómetro Bouyucos \\
\hline
\end{tabular}

\section{Análisis de la información}

Para el análisis de la información química se tomaron como referencia los valores reportados por el ICA, 1992; Salinas y García, 1985, reportado por, Rincón, 2010 y Rincón, 1999. Igualmente, las variables físicas se compararón con los valores de referencia reportados por Cortés y Malagón, 1984; Montenegro y Malagón, 1990 citado por Gutiérrez, 2014; Arango, 1998; Jaramillo, 2002 y Abaunza et al., 2006. Se realizó análisis de varianza y prueba de comparación de medias de Duncan para establecer si existían diferencias, se hizo a través de INFOSTAT versión 2014I Sofware libre.

Con el objeto de inferir sobre la riqueza de los sistemas se estimaron los índices de Simpson, Shannon-Wiener y Jaccard partiendo de las siguientes ecuaciones (Moreno, 2001).
Índice de Simpson: $\lambda=\Sigma p i^{2}$

pi: Abundancia proporcional de la especie i, es decir, nú mero de individuos de la especie i dividido entre el número total de individuos de la muestra. $\mathrm{pi}=\mathrm{Ni} / \mathrm{n}$

Índice de Shannon-Wiener:

Coeficiente de similitud de Jaccard:

$$
J_{J}=\frac{c}{a+b-c}
$$

$\mathrm{a}=\quad$ Número de especies presentes en el sitio $\mathrm{A}$

$b=\quad$ Número de especies presentes en el sitio B

$\mathrm{C}=$ Número de especies presentes en ambos sitios $\mathrm{A}$ y $\mathrm{B}$

El análisis estadístico de los datos se realizó por medio de Análisis de Componentes Principales (ACP) con el 
Programa Estadístico R versión 3.1.2 y se utilizó el paquete ADE4 (Análisis de Datos Ecológicos y Ambientales con Procedimientos Exploratorios Euclidianos) versión 1.4.5. Para la selección de las variables químicas y físicas se tuvo en cuenta las de mayor aporte a la formación de los dos primeros componentes, para esto se dividió por dos el máximo valor obtenido y se seleccionaron aquellas iguales o mayores a este (Velásquez et al., 2007). Se aplicó la Prueba de Montecarlo para evaluar la contribución de las variables a la separación entre sistemas analizados. (Rodríguez et al., 2013 y Gutiérrez, 2014).

Para la construcción de los índices químicos y físicos se redujeron las variables a valores comprendidos entre 0.1 y 1.0 mediante transformación homotética de acuerdo a lo propuesto por Velásquez et al., 2007, Rodríguez et al., 2013 y Gutiérrez, 2014, se tomaron los valores altos o bajos de cada variable teniendo en cuenta lo que era más adecuado para los sistemas de producción en la zona de estudio, para lo cual se utilizaron las siguientes ecuaciones:
Valores altos $\quad Y=0.1+\left(\frac{x-b}{a-b}\right) * 0,9$
Valores bajos $Y=1.1+\left(0.1+\left(\frac{x-b}{a-b}\right) * 0,9\right)$
Donde:
Y: Valor de la variable después de transformada
x: Valor de la variable a transformar
b: Mínimo valor obtenido para la variable en el muestreo
a: Máximo valor alcanzado por la variable

La variable transformada se multiplicó por su aporte a la formación del componente 1 y luego por su aporte a la formación del componente 2 (obtenido del ACP) los dos valores se sumaron y se sometieron nuevamente a transformación homotética y se promediaron obteniendo así los índices de calidad química y física; por último, se valoraron utilizando la escala propuesta por Cantú et al., 2007 y se determinó el grado de calidad química y física en que se encontraba cada sistema de uso del suelo.

\section{Resultados}

\section{Descripción química del suelo}

El menor valor de $\mathrm{pH}(4,59)$ lo arrojó el Bosque en P1 y el mayor $(5,30)$ el SAF en la misma profundidad, esta tendencia se mantuvo en $\mathrm{P} 2$, sin embargo, mientras el valor de $\mathrm{pH}$ en el Bosque y la pradera aumentó ligeramente, en el SAF disminuyó; los mayores valores promedio de $\mathrm{AlH}(2,48$ y $1,96 \mathrm{cmol} / \mathrm{kg}))$ los arrojó el bosque lo cual se relacionó con el menor pH que presentan los suelos de este sistema (tabla 2).

Entre tanto, el SAF arrojo el mayor valor promedio de $\mathrm{P}(38,54 \mathrm{mg} / \mathrm{kg})$ en P1y de S $(13,08 \mathrm{mg} / \mathrm{kg})$ en P2 los contenidos de $\mathrm{Ca}, \mathrm{Mg}$, $\mathrm{K}$ y $\mathrm{Na}$ fueron bajos en los tres sistemas evaluados. En cuanto a los elementos menores, se encontraron valores medios de B, Cu, Mn y Zn en el SAF, en el bosque y la pradera, los valores de $\mathrm{Mn}$ y $\mathrm{Zn}$ en P1 también fueron medios, mientras que para el resto de los elementos los valores estuvieron entre bajos y medios (tablas 2 y 3 ).

En este sentido, los valores bajos de $\mathrm{pH}$ limitaron la solubilidad de $\mathrm{Ca}, \mathrm{Mg}$ y K de acuerdo con lo expuesto por Jaramillo (2002) y Peña et al., (2009).

Los valores de azufre en el SAF fueron el resultado de la incorporación de residuos de cosecha del cultivo anterior (piña) así como de las adiciones de yeso, roca fósforica y fertilizacion (edáfica y foliar) intensiva (en la piña) que permitieron la acumulación de este elemento en el suelo, de acuerdo con González et al., (2005) el azufre orgánico proviene de residuos vegetales y animales, en algunos suelos representa más del $90 \%$ del azufre total sin embargo su velocidad de transformación en formas aprovechables es muy lenta lo cual explica el valor encontrado.

En todos los sistemas la $\mathrm{MO}$ fue alta, el mayor valor se obtuvo en la pradera $(4,73)$ y se relacionó con el aporte realizado por las heces del ganado y con la alta proporción (92\%) de oribatidos encontrados (tabla 7).

Por otra parte al comparar los resultados obtenidos con los rangos de nutrimentos reportados por Salinas y García (1985) para el establecimiento de especies forrajeras tolerantes a la acidez (Rincón, 1999), El SAF y la pradera arrojaron valores medios a muy altos en $\mathrm{P}, \mathrm{K}, \mathrm{Ca}$ y $\mathrm{Mg}$ y $\mathrm{Zn}$ en P1, como consecuencia de las adiciones de calcio y magnesio incorporadas al suelo utilizando cal dolomita como correctivo y de la fertilización con abono cafetero 17-6-18-2 que incrementó los niveles de $\mathrm{P}$ y K ; en la pradera el aporte de la orina y la bosta que deposita el ganado además de incrementar el contenido de materia orgánica aporta $\mathrm{P}$ y K, las cantidades promedio que se retornan al suelo mediante las excretas se encuentran entre 100 y $150 \mathrm{~kg} /$ año de $\mathrm{K}$ y de 10 a 20 $\mathrm{kg} / \mathrm{ha}$ de fosforo, (Rincón, 2010), en especies forrajeras que se han adaptado a suelos ácidos se requieren entre 10 y $20 \mathrm{~kg} / \mathrm{ha}$ de P para lograr el $80 \%$ de su máxima producción (Álvarez y Rincón, 2010).

Por consiguiente, el ACP separó los sistemas en función del $\mathrm{pH}, \mathrm{AlH}, \mathrm{Ca}, \mathrm{Mg}$, CICE y B, Na, S, Zn. Los 

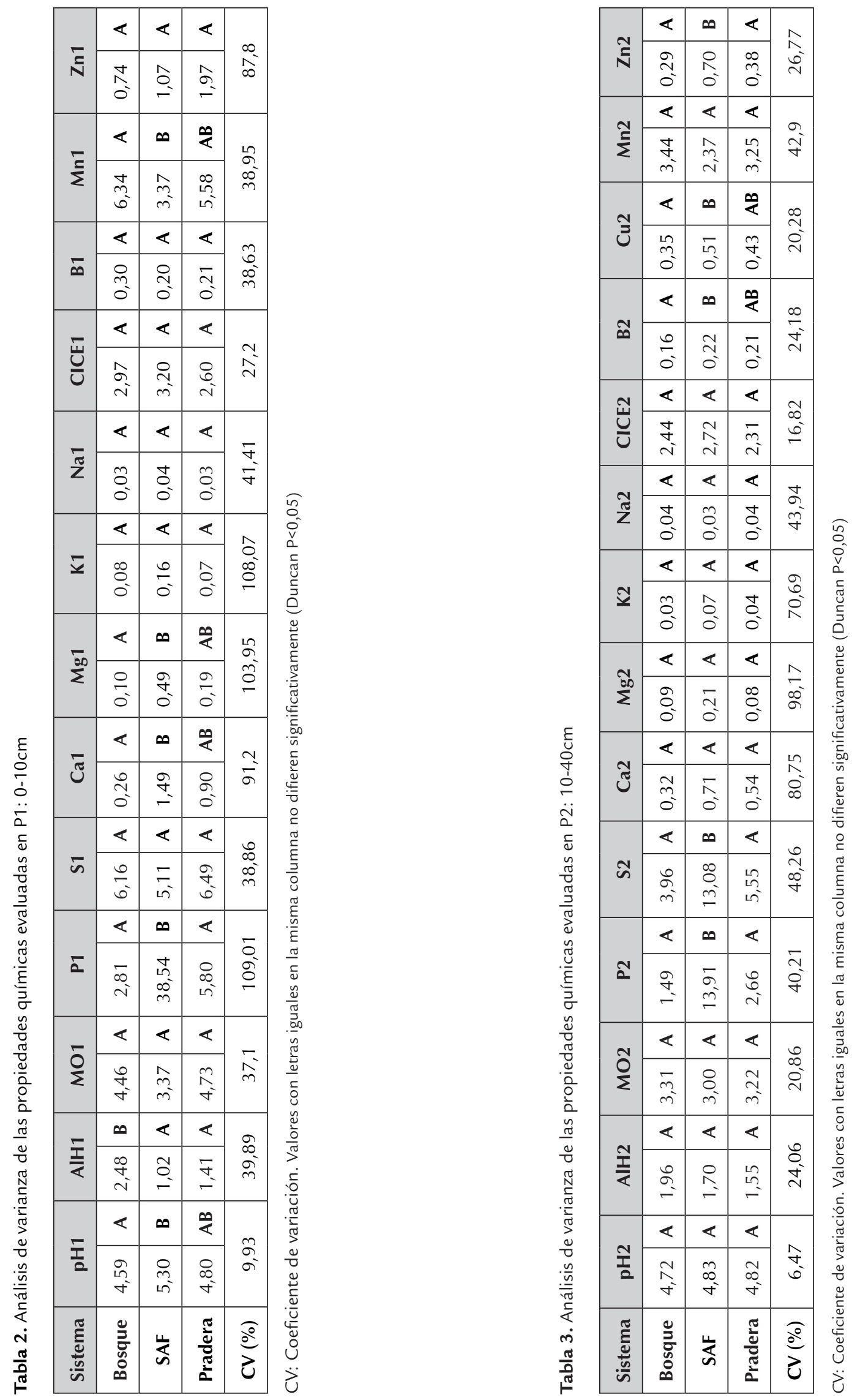

Propiedades químicas, físicas y biológicas del suelo, indicadores del estado de diferentes ecosistemas en terraza alta del Meta 
dos primeros componentes (C1 34,03 \% y C2 17,69 $\%$ ) explican el 51,72\% de la variabilidad. El primer componente separó los sistemas evaluados en función de AlH1 y el contenido de elementos mayores Ca1, Ca2, Mg1, Mg,2, CICE1, CICE2, P2, y pH1, siendo este último opuesto a la acidez intercambiable, mientras, el segundo componente los separó en función de B1, Na2 y S1, S2, K2 y Zn2, en este sentido C1 separó (significativamente) el SAF con valores mayores de pH1 (5,30), Ca1 (1,49), Mg1 (0,49), CICE $1(3,20)$ del Bosque con valores mayores AlH1 $(2,48)$ menor $\mathrm{pH}$ $1(4,59)$ y los menores valores de Ca1 $(0,26)$ y $\mathrm{Mg} 1$ $(0,10)$, mientras que, C2 separó el Bosque y la Pradera con contenidos mayores de $\mathrm{Na} 2(0,04)$ y $\mathrm{B} 1(0,30$ y $0,21)$, respectivamente, del SAF con valores mayores de S2 $(13,08)$, K2 $(0,07)$, Zn2 $(0,70)$ (Figura 1).

El $51,72 \%$ de la variabilidad entre los sistemas es significativa en un $26,78 \%(p<0,001$ Prueba de Montecarlo), en efecto, las variables químicas del suelo contribuyeron en un $26,78 \%$ a la separación entre sistemas. De acuerdo con la prueba de comparación de medias de Duncan existen diferencias significativas entre sistemas para las variables $\mathrm{pH} 1, \mathrm{AlH} 1, \mathrm{P} 1$, P2, S2 Ca1, Mg1, B2, Cu2, Mn1 y Zn2 (tablas 2 y 3). Teniendo en cuenta la contribución (peso) de cada una a la formación de los componentes, las variables indicadoras de calidad del suelo que contribuyen en mayor proporción a la explicación de las diferencias entre sistemas son pH1, AlH1, Ca1, Ca 2, Mg1, Mg 2, CICE1, CICE2, P2, B1, S2, K2, Na2, y Zn2. Igualmente, Doran y Parkin, 1994 y Nortcliff, 2002, citados por, Navarrete et al ., 2011 Astier et al., 2002, Velásquez et al .,2007, Rodríguez et al., 2013 y Gutiérrez, 2014 pro- ponen estas variables como indicadores que reflejan el estándar de fertilidad en los suelos y que son importantes en términos de la producción de los sistemas agrícolas (Figura 1).

\section{Descripción física del suelo}

La pradera y el SAF mostraron DA alta de $1,38 \mathrm{~g} / \mathrm{cm}^{3}$ y $1,34 \mathrm{~g} / \mathrm{cm}^{3}$ respectivamente, en el SAF este valor aumentó a $1,46 \mathrm{~g} / \mathrm{cm}^{3}$ en P2; igualmente, la DR en estos dos sistemas fue alta. Entre tanto, la porosidad total promedio en el SAF fue de $49,66 \%$ y $45,74 \%$ en $\mathrm{P} 1$ y P2, este cambio se relacionó con el aumento de DA; la proporción promedio de macroporos paso de $11,30 \%$ a $8,21 \%$ de P1 a P2, lo cual sugiere que existe un impedimento importante en el crecimiento de las raíces y la transmisión de agua en el perfil. Valores de macroporosidad menores de $10 \%$ restringen el desarrollo radical (Jaramillo, 2002); según la FAO, 2009 valores menores a $1,3 \mathrm{~g} / \mathrm{cm}^{3}$ indican buena porosidad, mientras que valores superiores reflejan dificultades para el crecimiento de las raíces, baja aireación e infiltración (tablas 4 y 5 ).

Por otra parte, en el bosque se encontraron valores de PT entre 50 y $60 \%$ y $\mathrm{DA}<1,3 \mathrm{~g} / \mathrm{cm}^{3}$, contrario a la pradera que presentó PT $<50 \%$ y DA $>1,3$; en P1 fue mayor la proporción de mesoporos que en la pradera es decir existió un mejor almacenamiento de agua en el bosque (tablas 4 y 5). De la misma manera en la tabla 5 se aprecia la relación entre mesoporosidad y humedad disponible, menor porcentaje de mesoporos se reflejó en los contenidos bajos de humedad disponible (Jaramillo, 2000).

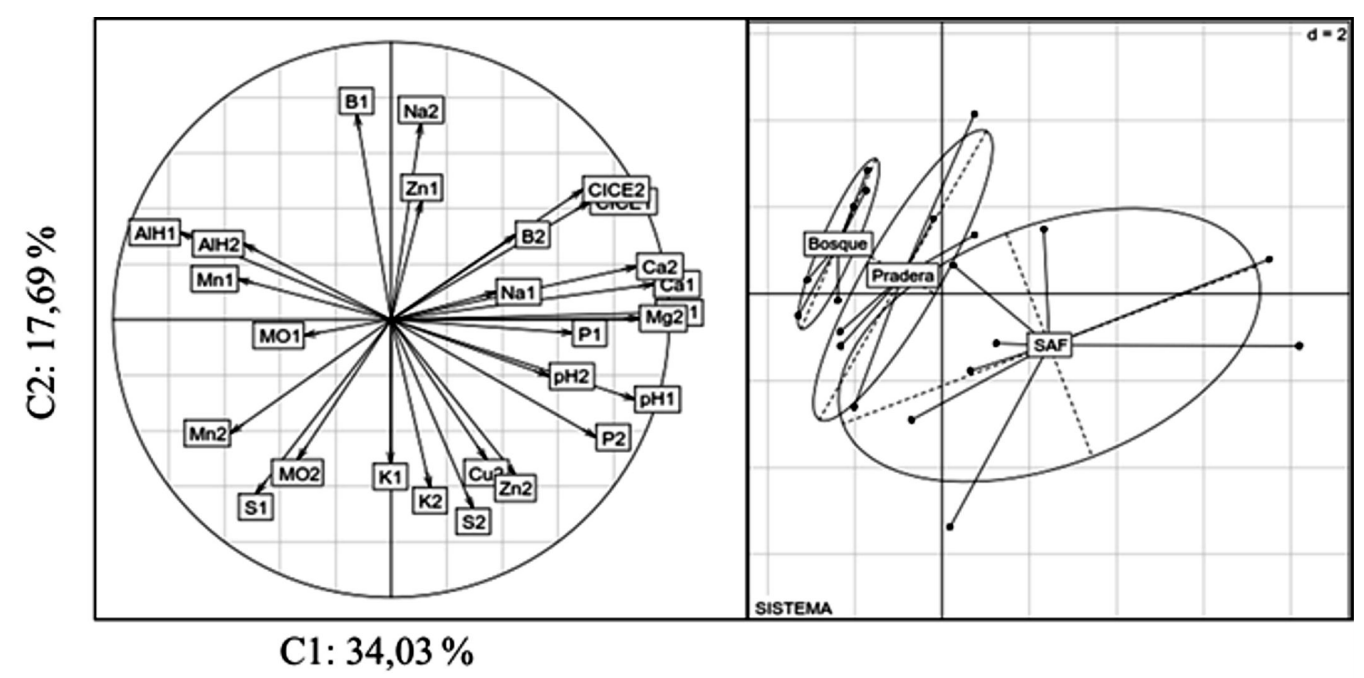

Figura 1. Proyección de las variables químicas en el círculo de correlación en función de su aporte a la formación de los C1 y C2 y distribución de los sistemas evaluados. 

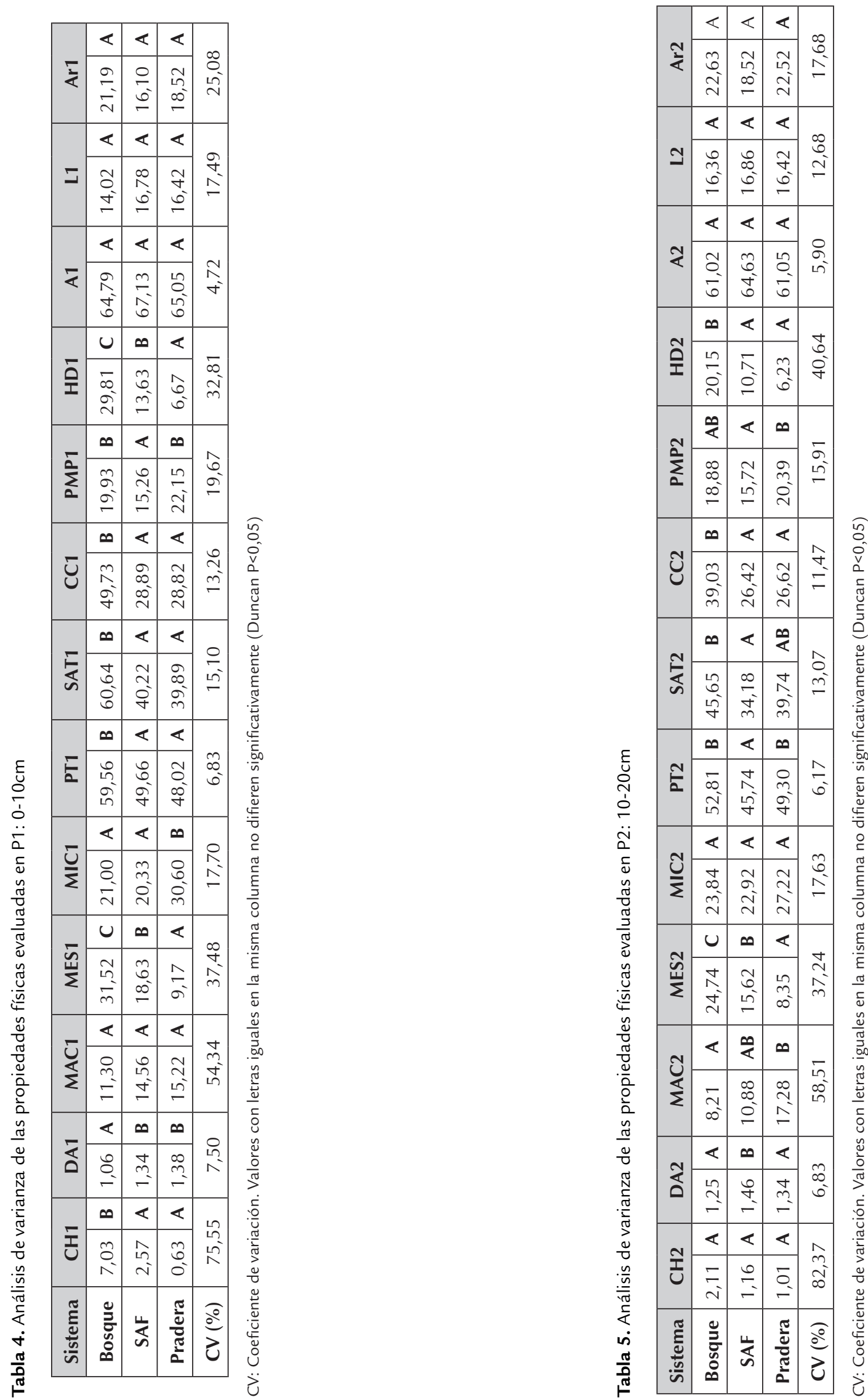
Cabe resaltar el cambio textural que se observó en la pradera de franco arenoso (FA) a franco arcillo-arenoso (FArA) al profundizar en el perfil, este contraste textural puede generar interrupción o reducción en el tamaño de los poros que desacelera el flujo de agua y la infiltración (Jaramillo, 2002), en este sentido, la proporción de microporos tres veces mayor que los mesoporos afectó la conductividad hidráulica y el contenido de humedad disponible; a los mesoporos se les conoce como poros de almacenamiento, retienen el agua que puede ser absorbida por los cultivos, en cambio, los microporos retienen tan fuerte el agua que esta no puede ser tomada por las plantas (tablas 7 y 8 ).

Lo anterior sumado a valores de resistencia a la penetración mayores a 1,4 Mpa en los primeros $5 \mathrm{~cm}$ del perfil en la pradera (figura 2) evidenciaron un problema de adensamiento o compactación como consecuencia del sobrepastoreo del ganado ligado a la baja calidad de forraje por la falta de manejo. La compactación del suelo producto de la pérdida del espacio poroso por la fuerte presión externa que ejerce el animal, concuerda con lo encontrado en algunas fincas del piedemonte donde la densidad aparente fue de $1,42 \mathrm{~g} / \mathrm{cm}^{3}$ (en los primeros $10 \mathrm{~cm}$ ) y aumentó en profundidad y la porosidad de $45 \%$ (entre10 y $20 \mathrm{~cm}$ ) (Rincón, 2010).

De otro lado, en el SAF se encontraron valores de resistencia a la penetración $>1,3 \mathrm{Mpa}$ a partir de los 15 $\mathrm{cm}$ de profundidad del perfil que junto con el comportamiento de la densidad aparente en profundidad evidenciaron la existencia de una capa compacta consecuencia de la mecanización del suelo para la siembra del cultivo anterior (Piña), contrario a lo que se encontró en el bosque donde la resistencia a la penetración estuvo entre 0,2 y 1,3 Mpa en los primeros $30 \mathrm{~cm}$ del perfil (figura 2). Estos resultados corroboran lo encontrado por Baquero et al., (2001) en suelos de San Carlos de Guaroa Meta, cultivados por más de 20 años, donde la resistencia a la penetración alcanzó valores entre 1,4 y $1,5 \mathrm{Mpa}$ (entre 10 y $16 \mathrm{~cm}$ ), mientras en lotes abandonados fue mucho mayor (1,5 Mpa en los primeros centímetros) y en bosque 0,7 Mpa.

En efecto, el ACP separo los sistemas en función de la densidad y el contenido de agua en el suelo, los dos primeros componentes explicaron el 65,79\% (C1 $37,93 \%$ y C2 $27,86 \%$ ), el primer factor separó los sistemas en función de la porosidad (PT y MES), saturación (SAT), capacidad de campo (CC), humedad disponible (HD) y la densidad aparente (DA); el segundo factor en función de la microporosidad (MIC), punto de marchitez permanente (PMP), contenido de arcilla (Ar) y el contenido de arena (A). Siendo la densidad aparente opuesta la porosidad total (figura 3).

En este sentido el primer componente separó el sistema bosque con los mayores valores de $\mathrm{CH} 1(7,03)$, mesoporosidad ( $31,52 \%$ y $24,74 \%)$, porosidad total $(59,56 \%$ y $52,81 \%)$, saturación $(60,64$ y 45,65$)$, capacidad de campo $(49,73 \%$ y $39,03 \%)$, humedad disponible $(29,81 \%$ y $20,15 \%)$ del SAF y pradera con mayores valores de densidad aparente 1,34 y 1,38 arrojados en $\mathrm{P} 1$ y 1,46 y 1,34 en $\mathrm{P} 2$, respectivamente; el segundo componente separó el sistema pradera con valores más altos de microporosidad (MIC 1: 30,60 \% y MIC2: $27,22 \%)$ y punto de marchitez permanente (PMP1: 22,15 \%, PMP2: 20,39) del bosque y el SAF (figura3).

Las variables físicas contribuyeron en un $43,49 \%$ ( $p<0,001$ Prueba de Montecarlo) a la separación entre sistemas, El SAF y la pradera son sistemas que se encuentran en algunas de las características mientras que el bosque se distancia de ellos considerablemente formando dos conglomerados; la comparación de medias de Duncan permitió diferenciar significativamente el sistema bosque a través de las variables $\mathrm{CH} 1$, MES1, MES2, PT1, SAT1, CC1, CC2, HD1 y HD2 de los otros sistemas evaluados (tablas 4 y 5 y, figura 3 ).

Por consiguiente las variables físicas que contribuyeron en mayor proporción a la diferenciación entre sis-
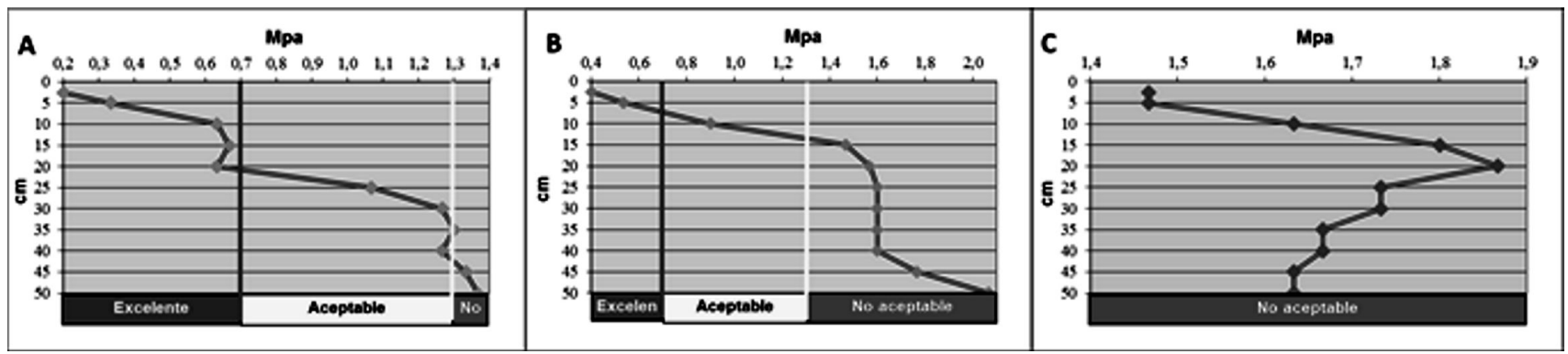

Figura 2. Resistencia a la penetración expresada en megapascales (Mpa) evaluada en el Bosque (A), el SAF (B) y la pradera (C) 


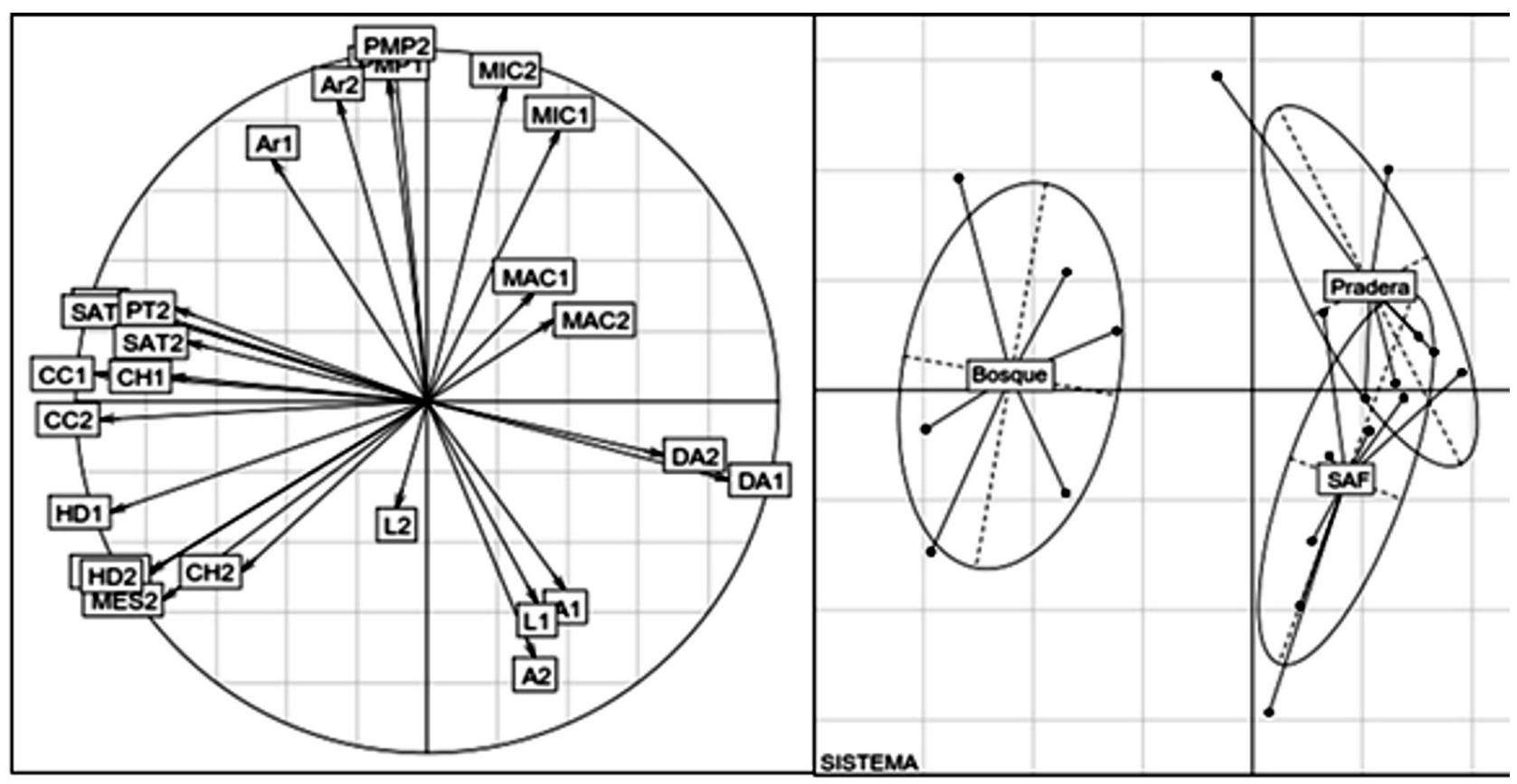

\section{$\mathrm{C} 1: 37,93 \%$}

Figura 3. Proyección de las variables físicas en el círculo de correlación en función de su aporte a la formación de los C1 y C2 y distribución de los sistemas evaluados

temas fueron $\mathrm{CH}$, DA, MES, MIC, PT, SAT, CC, HD, PMP, A y Ar y, se relacionaron con la manera como el suelo acepta retiene y proporciona el agua a las plantas, es decir, con la infiltración y movimiento del agua dentro del perfil y, el intercambio gaseoso; además, con las condiciones que pueden limitar la emergencia de la plántula y el crecimiento del sistema radical. Estas variables están de acuerdo con las propuestas por Doran y Parkin, 1994 y Nortcliff, 2002, Navarrete et al., 2011 Astier et al., 2002, Velásquez et al., 2007 Rodríguez et al., 2013 y Gutiérrez, 2014.

\section{Descripción biológica del suelo}

Se encontraron 11 familias de mesoinvertebrados (Carabeidae, Cecidomidae, Cicindellidae, Coccidae, Entomobryidae, Forficulidae, Formicidae, Gelechidae, Liposcelidae, Nitidulidae, Phoridae, Pseudococcidae, Rhinotermitidae, Staphylinidae y Trogiidae) y dos órdenes (Acaridida y Oribatida), asociados a los tres sistemas; $59,26 \%$ en el SAF, 22,22\% en el bosque y $18,52 \%$ en la pradera, igualmente, el mayor número de individuos se recolectó en el SAF, seguido del bosque y la pradera, la prueba de comparación de medias de Duncan mostró diferencias significativas entre el número promedio de familias encontradas en cada sistema. No obstante, el promedio de individuos por metro cuadrado (ind $/ \mathrm{m}^{2}$ ) no arrojó diferencias (tabla 6).
Valores con letras iguales en la misma columna no difieren significativamente (Duncan $\mathrm{P}<0,05$ )

En cuanto a los grupos funcionales encontrados, la proporción de ingenieros del ecosistema fue mayor en el bosque $(83,72 \%)$, seguido del SAF $(42,65 \%)$ y de la pradera $(16,67 \%)$, este grupo estuvo conformado en su mayoría por hormigas (formicidae) insectos sociales capaces de explorar eficientemente el suelo y producir estructuras órgano minerales hábitat de otros microorganismos. Por otro lado, la proporción de micropredadores fue mayor en la pradera $(66,67 \%)$ seguido del $\operatorname{SAF}(30,88 \%)$ y del bosque $(6,98 \%)$ (tabla 7$)$.

Según Lavelle (1996) la microflora intestinal asociada a los ingenieros del ecosistema es eficiente para descomponer el material que consumen, en termitas se reportó asimilación hasta de 93\% del material ingerido.

Por otro lado, los micropredadores participan en redes microalimentarias con varios niveles de herbívoros microbianos y uno o dos niveles de depredadores $y$, no forman estructuras; al aumentar la complejidad de este grupo se acelera la mineralización de la materia orgánica.

Adicionalmente, el $92 \%$ de los micropredadores en la pradera fueron oribatidos mientras en el SAF domina- 




ron los acáridos y en el bosque aunque hubo menor cantidad de micropredadores se mantuvo igual proporción oribatidos-acáridos (tabla 7); los oribatidos se ven afectados por las prácticas de silvicultura por lo tanto pueden ser buenos indicadores a la hora de evaluar las alteraciones del medio natural (Momo y Falco, 2003; Genoy et al., 2013 y Iturrondobeitia et al., 2004)

Entretanto, el ACP mostró una tendencia a separar los sistemas evaluados, sin embargo, las variables seleccionadas no contribuyeron significativamente (Prueba de Montecarlo $p<0,14$ ) (figura 4) lo cual se constató al calcular el coeficiente de similitud de Jaccard 0,33 (SAF-bosque), 0,22 (bosque-pradera) y 0,19 (SAF-pradera); por otro lado, hubo mayor uniformidad en el $\mathrm{SAF}$ que en la pradera y el bosque, ya que, el índice de Shannon fue 2,06 en el SAF, 1,16 en la pradera y 0,70 en el bosque además, el índice de Simpson fue menor en el $\operatorname{SAF}(0,20)$ respecto a los sistemas pradera $(0,41)$ y bosque $(0,70)$, ya que este último sistema arrojó alta dominancia de la familia formicidae.

Por su parte, el mayor número de especies de HFMA se encontró en el SAF (11) seguido del bosque (9) y la pradera (8). En el SAF se identificaron Acaulospora clarum, Acaulospora spinosa, Entrophosphora colombiana, Gigaspora margarita, Glomus clarum, Glomus etunicatum, Glomus fulvum, Glomus geosporum, Glomus manihotis, Glomus tenebrosum, Sclerocystis dussi y Sclerocystis sp; en el bosque: Acaulospora denticulata, Entrophosphora colombiana, Gigaspora margarita, Glomus clarum, Glomus etunicatum, Glomus fulvum, Glomus geosporum, Glomus manihotis, Glomus tenebrosum y Sclerocystis dussi mientras que en la pradera: Acaulospora monrrow, Entrophosphora colombiana, Glomus clarum, Glomus geosporum, Glomus manihotis, Glomus tenebrosum, Sclerocystis dussi y Sclerocystis $s p$. De igual manera, el SAF arrojó el mayor número de esporas (43,50 esporas/g de suelo) (tabla 8)

Asimismo, se encontraron el mayor número de generos de hongos en el SAF (20) seguido de la pradera (10) y del bosque (9). Se identificaron en el SAF: Aspergillus niger, Aspergillus parasitivus, Aspergillus sclerotium, Fusarium sp, Mucor sp, Mycogone sp, Penicillium citrinium, Penicillium claviforme, Penicillium decumbens, Penicillium digitatum, Penicillium estrictum, Penicillium flavus, Penicillium frecuentans, Penicillium italicum, Penicillium jensensii, Penicillium junicullosum, Penicillium lanosum, Penicillium lividum, Trichoderma koningii, y Trichoderma viridae; en la pradera: Aspergillus fumigatum, Fusarium sp, Mucor sp, Mycogone sp, Penicillium digitatum, Penicillium flavus, Penicillium lanosum, Penicillium lividum, Trichoderma koningii, Trichoderma viridae y en el bosque: Aspergillius flavus, Fusarium sp, 
Tabla 7. Grupos funcionales de mesoinvertebrados presentes en los sistemas evaluados.

\begin{tabular}{|c|c|c|c|}
\hline Sistema & G. Funcional & Orden/Familia & $\begin{array}{c}\text { Proporción } \\
(\%)\end{array}$ \\
\hline \multirow{5}{*}{ Bosque } & Micropredadores & $\begin{array}{l}\text { Oribatida } \\
\text { Acaridida }\end{array}$ & 6,98 \\
\hline & Predadores & Carbidae & 2,33 \\
\hline & Saprofago & Forficulidae & 4,65 \\
\hline & $\begin{array}{l}\text { Ingenieros del } \\
\text { ecosistema }\end{array}$ & Formicidae & 83,72 \\
\hline & $\begin{array}{c}\text { Transformadores de } \\
\text { hojarasca }\end{array}$ & Gelechidae & 2,33 \\
\hline \multirow{6}{*}{ SAF } & Micropredadores & $\begin{array}{c}\text { Oribatida } \\
\text { Acaridida } \\
\text { Entomobryidae } \\
\text { Staphylinidae }\end{array}$ & 30,88 \\
\hline & Predadores & $\begin{array}{l}\text { Carabidae } \\
\text { Cicindelidae }\end{array}$ & 7,35 \\
\hline & Saprofago & $\begin{array}{l}\text { Forficulidae } \\
\text { Phoridae }\end{array}$ & 7,35 \\
\hline & $\begin{array}{l}\text { Ingenieros del } \\
\text { ecosistema }\end{array}$ & $\begin{array}{c}\text { Formicidae } \\
\text { Rhinotermitidae }\end{array}$ & 42,65 \\
\hline & Fitofago & $\begin{array}{l}\text { Cecidomyiidae } \\
\text { Pseudococcidae }\end{array}$ & 5,88 \\
\hline & $\begin{array}{c}\text { Transformadores de } \\
\text { Hojarasca }\end{array}$ & $\begin{array}{l}\text { Liposcelidae } \\
\text { Trogiidae }\end{array}$ & 5,88 \\
\hline \multirow{4}{*}{ Pradera } & Micropredadores & $\begin{array}{c}\text { Oribatida } \\
\text { Staphylinidae }\end{array}$ & 66,67 \\
\hline & Fitofago & Coccidae & 5,56 \\
\hline & $\begin{array}{l}\text { Ingenieros del } \\
\text { ecosistema }\end{array}$ & Formicidae & 16,67 \\
\hline & $\begin{array}{c}\text { Transformadores de } \\
\text { hojarasca }\end{array}$ & Nitidulidae & 11,11 \\
\hline
\end{tabular}

Mucor sp, Penicillium digitatum, Penicillium flavus, Penicillium frecuentans, Penicillium lanosum, Trichoderma koningii y Trichoderma viridae. Por último, se identificaron tres géneros de bacterias Bacillus sp, Clostridium $s p$ y Pseudomonas $s p$ asociados a los sistemas evaluados, a continuación se presenta la población de los microorganismos en cada sistema (tabla 8).

Los procesos del suelo están afectados primero por el clima, luego por factores edáficos (principalmente contenido de arcilla y el estado de nutrientes), por la calidad del material producido a partir de la comunidad vegetal fuente de energía y nutrientes y finalmente por la asociación de macro y microorganismos, en este sentido, las estructuras producidas por invertebrados como ingenieros del ecosistema sirven de incubadoras para las actividades microbianas, en efecto la alta proporción de ingenieros del ecosistema encontrada en el bosque fue asociada a la mayor proporción de actinomicetos, por otra parte la mayor población de 


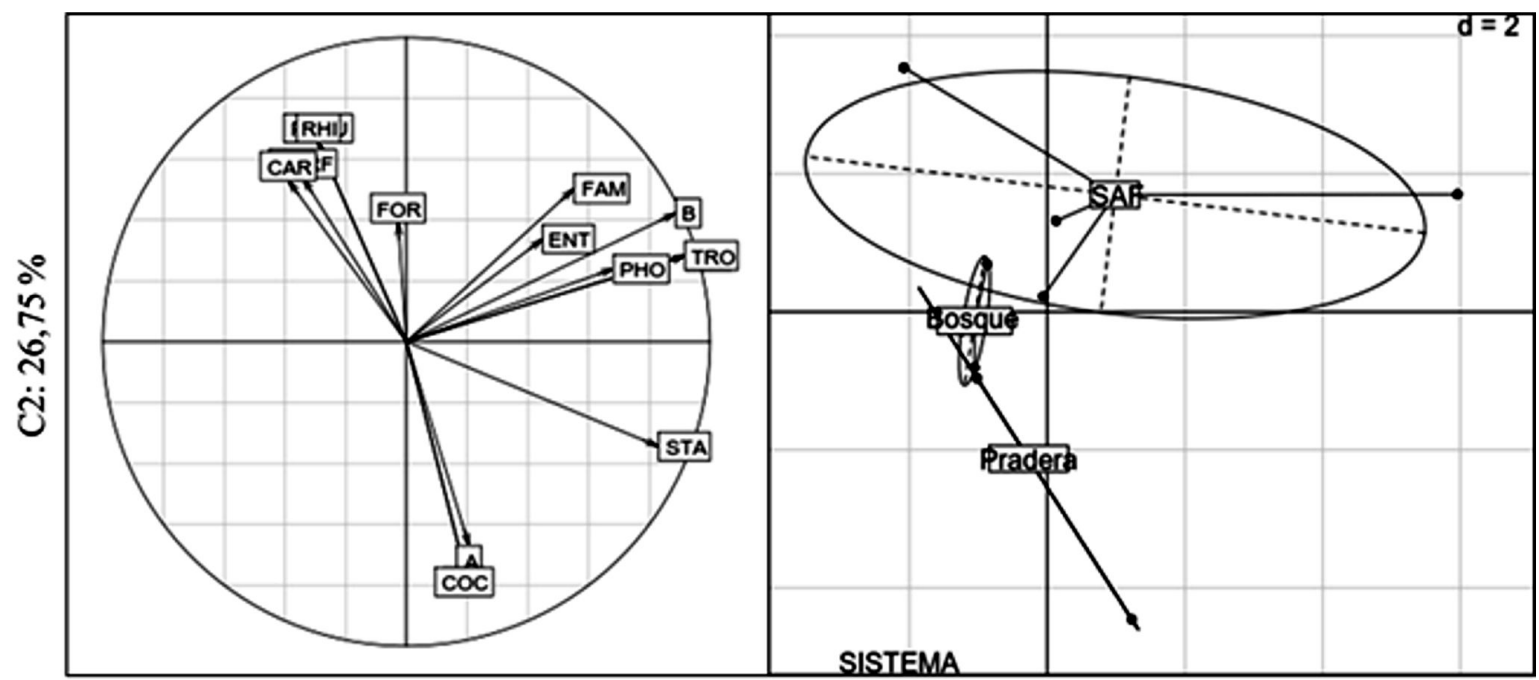

$\mathrm{Cl}: 31,22 \%$

Figura 4. Proyección de las familias de mesoinvertebrados en función de su aporte a la formación de los C1 y C2 y distribución de los sistemas evaluados.

Tabla 8. Población de microorganismos encontrados en cada sistema evaluado

\begin{tabular}{|l|c|c|c|c|c|c|c|}
\hline \multicolumn{1}{|c|}{ Sistema } & $\begin{array}{c}\text { HFMA } \\
(\mathbf{g e n})\end{array}$ & $\begin{array}{c}\text { HFMA } \\
(\mathbf{e s p} / \mathbf{g})\end{array}$ & $\begin{array}{c}\text { Actinomicetos } \\
(\mathbf{l o g} \text { UFC/g) }\end{array}$ & $\begin{array}{c}\text { Bacterias } \\
(\mathbf{g e n})\end{array}$ & $\begin{array}{c}\text { Bacterias } \\
(\mathbf{l o g} \text { UFC/g) }\end{array}$ & $\begin{array}{c}\text { Hongos } \\
(\mathbf{g e n})\end{array}$ & $\begin{array}{c}\text { Hongos } \\
\text { (log UFC/g) }\end{array}$ \\
\hline Bosque & 9 & 38,67 & 11,13 & 3 & 9,37 & 9 & 7,67 \\
\hline SAF & 11 & 43,50 & 8,54 & 3 & 9,43 & 20 & 8,94 \\
\hline Pradera & 8 & 33,33 & 7,30 & 3 & 8,92 & 10 & 8,37 \\
\hline
\end{tabular}

micorrizas en el SAF se relacionó con la mayor asimilación de nutrientes como el fosforo.

Las variables seleccionadas en cuanto a microoorganismos no permitieron discriminar entre los sistemas, de acuerdo con la Prueba de Montecarlo $(p<0,41)$.

\section{Índices de Calidad}

El índice químico del SAF fue significativamente mayor respecto a los otros sistemas debido a que presentó valores altos de $\mathrm{pH} 5,30$ y acidez intercambiable baja 1,02 Cmol/kg; además, contenidos de Ca1 1,49 $\mathrm{Cmol} / \mathrm{kg}$, Ca2 0,71 Cmol/kg, Mg1 0,49 Cmol/kg, Mg2 0,21 Cmol/ $\mathrm{kg}, \mathrm{S} 2: 13,08 \mathrm{mg} / \mathrm{kg}$ y Zn $20,70 \mathrm{mg} / \mathrm{kg}$ mayores como consecuencia del manejo químico a que se sometió el suelo para el establecimiento y mantenimiento del sistema productivo, mientras que, el bosque reflejó las características propias de los oxisoles del piedemonte llanero, $\mathrm{pH}$ bajo $(4,59)$, acidez intercambiable alta $(2,48 \mathrm{Cmol} / \mathrm{kg})$ y contenido de bases bajo, este sistema no recibió ningún aporte exter- no de nutrientes; por su parte, el índice en la pradera fue, bajo resultado de la falta de manejo (tablas 5, 6 y 12). Estos resultados corroboran lo encontrado por Jamioy (2011) y Gutiérrez (2014) en oxisoles donde los mayores índices de calidad química estuvieron ligados a incrementos en el $\mathrm{pH}$, menores valores de acidez intercambiable y contenidos de calcio y magnesio mayores

Tabla 9. Índice de calidad química y física para cada sistema de producción evaluado.

\begin{tabular}{|l|c|c|c|c|}
\hline \multirow{2}{*}{$\begin{array}{l}\text { Sistemas de } \\
\text { Producción }\end{array}$} & \multicolumn{4}{|c|}{ Índice de Calidad } \\
\cline { 2 - 5 } & \multicolumn{2}{|c|}{ Químico } & \multicolumn{2}{c|}{ Físico } \\
\hline Bosque & 0.15 & A & 0.84 & B \\
\hline SAF & 0.54 & B & 0.32 & A \\
\hline Pradera & 0.25 & A & 0.24 & A \\
\hline CV $(\%)$ & \multicolumn{2}{|c|}{50.11} & \multicolumn{2}{c|}{25.32} \\
\hline
\end{tabular}


Sin embargo, el índice físico en el Bosque fue 0.68, significativamente mayor a los demás sistemas evaluados debido a que arrojó menor densidad aparente (DA1: 1,06 g/cm3 DA2: 1,25 g/cm); porosidad total mayor al $50 \%$ y acercándose al $60 \%$ en P1; contenido de mesoporos mayor (MES1: 31,52\% y MES 2:24,74 \%); altos valores de saturación (SAT1: 60,64 \% y SAT $2: 45,65 \%$ ) y capacidad de campo alta (CC1: $49,73 \%$ y CC2: 39,03\%). Cabe anotar que la condición física se reflejó en el valor de resistencia a la penetración menor o cercana a 1,3 Mpa. No obstante, el SAF presentó un índice bajo que resultó del incremento de la densidad aparente de 1,34 a 1,46 en los primeros 20 $\mathrm{cm}$ del perfil y afecto la distribución de poros, en este sentido, la resistencia a la penetración fue mayor a 1,3 Mpa a la misma profundidad. Por su parte en la pradera la densidad aparente fue alta y a los $5 \mathrm{~cm}$ se evidencio una capa compacta y, por lo tanto la resistencia a la penetración fue mayor de 1,4 y se incrementó con la profundidad (tablas 4, 5 y 9).

Tabla 10. Clases de Calidad de Suelos. Cantú et al., 2007.

\begin{tabular}{|l|c|c|}
\hline Índice de calidad de suelos & Escala & Clases \\
\hline Muy alta calidad & $0.80-1.00$ & 1 \\
\hline Alta calidad & $0.60-0.79$ & 2 \\
\hline Moderada calidad & $0.40-0.59$ & 3 \\
\hline Baja calidad & $0.20-0.39$ & 4 \\
\hline Muy baja calidad & $0.00-0.19$ & 5 \\
\hline
\end{tabular}

De acuerdo con la escala de calidad de suelo (tabla 10) propuesta por Cantú et al., (2007) el SAF mostró moderada calidad química debido a valores altos de $\mathrm{pH}$, baja acidez intercambiable y contenidos de calcio y magnesio mayores respecto a los demás sistemas y, baja calidad física reflejo del incremento de densidad aparente en profundidad, resistencia a la penetración $>1,3 \mathrm{Mpa}$ entre los 15 y $20 \mathrm{~cm}$ de profundidad, contenido de microporos mayor que los mesoporos en ambas profundidades y humedad disponible menor, mientras que, el bosque presentó muy baja calidad química característica de este tipo de suelos oxisoles y muy alta calidad física en concordancia con la densidad aparente y resistencia a la penetración menores, porosidad total media, saturación entre media y alta y capacidad de campo alta; en efecto, la pradera mostró baja calidad química debido a menores contenidos de K y Zn2 y baja calidad física por la alta densidad aparente y resistencia a la penetración $>1,3$ Mpa y que se incrementa en profundidad, reflejo de una capa com- pacta a los $5 \mathrm{~cm}$, baja conductividad hidráulica, mayor contenido de microporos y menor contenido de humedad disponible (tablas 2,3,4,5 y 9).

\section{Conclusiones}

1. Los indicadores físicos que permitieron separar los sistemas evaluados son densidad aparente, conductividad hidráulica, porosidad, (Distribución), saturación, capacidad de campo, punto de marchitez permanente, contenido de arena y resistencia a la penetración.

2. Los indicadores químicos que explicaron las diferencias entre los sistemas evaluados fueron $\mathrm{pH}$, aluminio intercambiable, calcio, magnesio, CICE, fósforo potasio, azufre, zinc y sodio.

3. Los indicadores físicos y químicos seleccionados permitieron diferenciar entre los tres sistemas de producción evaluados (Bosque, SAF y Pradera), es decir, son sensibles a los cambios en el uso del suelo

4. El análisis de la comunidad de mesoinvertebrados y microorganismos (hongos, bacterias, actinomicetos y HFMA) evidenció la complejidad de las interacciones de la fauna edáfica en los sistemas evaluados y no permitió diferenciarlos

\section{Referencias}

Abaunza CA, Yasmin SC, Barragán W. (2006). Identificación y valoración de factores biofísicos del suelo y pasturas que limitan la actividad ganadera para la generación y estimación de indicadores de degradación en los departamentos de Córdoba, Sucre y Atlántico. Informe parcial. Proyecto: Generación y estimación de indicadores de degradación para la valoración de praderas en Sistemas de Producción de Carne en los departamentos de Córdoba, Sucre y Atlántico. Corpoica.

Álvarez M, Rincón A. (2010). Características Agroecológicas de la Orinoquía Colombiana. En Rincón, A. \& Jaramillo, C. A. (Ed/s). Establecimiento, Manejo y Utilización de Recursos Forrajeros en Sistemas Ganaderos de Suelos Ácidos (pp. 9-25). Villavicencio: Produmedios.

Amézquita E, Molina DL, Chávez LF, Ricaurte J. (2000, 23-25 de agosto). "La Construcción de una Capa Arable: Práctica Clave para la Agricultura Sostenible en Suelos de la Altillanura Colombiana" [conferencia], II Seminario de Agrociencia y Tecnología Siglo XXI - Orinoquía Colombiana CORPOICA-PRONATTA, Villavicencio.

Arango JC. (1998). Relación suelo- agua- planta. Universidad Nacional de Colombia. Medellín.

Astier M, Mass M, Etchevers J. Derivación de Indicadores de Calidad de Suelos en el Contexto de La Agricultura Sustentable. Agrociencia. 2002;36(005):605-620. 
Bagyaraj JD, Sturmer SL. 2012. Hongos micorrizógenos arbusculares (HMA). En: Moreira F M, Huising E J y Bignell D E (editores). Manual de biología de suelos tropicales. Muestreo y caracterización de la biodiversidad bajo suelo. Secretaria de Medio Ambiente y Recursos Naturales (SEMARNAT). Instituto Nacional de Ecología (INE). México D.F. p. 217-233.

Baquero E, Aristizábal D, Rendón W, Salamanca CR. (2001). Manejo conservacionista de los suelos arroceros de la Orinoquia colombiana. Boletín Técnico No. 32. CORPOICA-PRONATTA.

Bautista A, Etchevers J, Del Castillo RF, Gutiérrez C. La Calidad del Suelo y sus Indicadores. Revista Científica y Técnica de Ecología y Medio Ambiente. Ecosistemas. 2004;13(2):90-97.

Bueno GA. (2010). Sistemas Silvopastoriles Arreglos y Usos. En Rincón, A. \& Jaramillo, C. A. (Eds). Establecimiento, Manejo y Utilización de Recursos Forrajeros en Sistemas Ganaderos de Suelos Ácidos (pp. 201-229). Villavicencio: Produmedios.

Cantú MP, Becker A, Bedano JC, Schiavo HF. Evaluación de la Calidad de Suelos mediante el uso de Indicadores e Índices. Ciencia del Suelo. 2007;25(2):173-178.

Cortés A, Malagón D. (1984). Los levantamientos agrológicos y sus aplicaciones múltiples. Universidad Jorge Tadeo Lozano. Bogotá

DANE. (2015). Informe de Coyuntura Económica Regional. Villavicencio:DANE

FAO. (2009). Guía para la descripción de suelos. Roma.

FAO. (2009). Manual de prácticas integradas de manejo y conservación de suelos. Boletín de tierras y aguas 8. Pp. 40-57.

Genoy M, Castillo JA, Bacca T. Ácaros Oribátidos presentes en seis sistemas de uso del suelo en Obonuco, Pasto (Nariño). Boletín Científico, Museo de Historia Natural. 2013;17(2):60-68.

González H, Sadeghian S, Mejía B. (2005). El azufre en los suelos de la zona cafetera colombiana, Avances Técnicos 332, Cenicafe.

Gutiérrez AJ. (2014). Aportes a la Rehabilitación Ecosistémica de Áreas Riparias con Énfasis en Calidad de Suelos y Producción Dendroenergética, por Medio de Arreglos Agroforestales en Zonas Ganaderas del Piedemonte Llanero. (Tesis inédita de Maestría). Escuela de Formación de Investigadores y Capacitación en Agricultura Tropical. EFICAT. Universidad de Ciencias Ambientales y Aplicadas UDCA. Bogotá

Gutiérrez AJ. (2011). Espacialización y determinación de zonas con potencial para el establecimiento y desarrollo de actividades agropecuarias en el departamento del Meta

Gutiérrez S, Valderrama J. Composición florística y dinámica de un bosque primario y uno secundario en tres estados sucesionales en sitios contrastantes de la región del Pacifico Medio, Colombia. Colombia Forestal 2000;6(13):52-62.

Hernández AN. (2005). Identificación de micorrizas vesículo-arbusculares nativas asociadas al cultivo del plátano (Musa sp) y su evaluación a nivel de laboratorio e invernadero en la Universidad de los Llanos Orientales. Universidad de los Llanos, Villavicencio, Meta.

ICA. (1992). Fertilización en diversos cultivos. Quinta aproximación. Manual de asistencia 25
Instituto Geográfico Agustín Codazzi (IGAC). (2004). Estudio General de Suelos y Zonificación de Tierras del Departamento del Meta.

Iturrondobeitia JC, Caballero Al, Arroyo J. (2004). Avances en la utilización de los Ácaros Oribátidos como indicadores de las condiciones Edáficas. Suplemento. Universidad del País Vasco.

Jamioy D. (2011). Propuesta de Indicadores de Calidad Edafológicos para Valorar la Influencia de los Sistemas Productivos Sobre Algunas Propiedades Físicas y Químicas en Suelos Oxisoles del Piedemonte Llanero Colombiano. (Tesis inédita de Maestría). Universidad Nacional de Colombia, Palmira.

Jaramillo DF. (2002). Introducción a la ciencia del suelo. Universidad Nacional de Colombia. Medellín.

Lavelle P. Diversity of soil fauna and ecosystem function. Biology International 1996;33:3-16.

Martella M, Trumper E, Bellis L, Renison D, Giordano P, Bazzano G y Gleiser R. Manual de Ecología Evaluación de la biodiversidad. Reduca. Argentina. Serie Ecología. 2012;5(1):71-115.

Momo F, Falco L. (2003). La Mesofauna del Suelo. Biología y Ecología. Universidad Nacional de Luján. Argentina.

Monroy H, Salamanca C, Cano C, Moreno L, Orduz J. Influencia de las Coberturas en Cultivos de Cítricos sobre los Hongos Formadores de Micorrizas Arbusculares en Oxisoles del Piedemonte Llanero Colombiano, CORPOICA Ciencia y Tecnología Agropecuaria. 2013;14(1):53-65.

Moreno CE. (2001). Métodos para medir la biodiversidad. M\&TManuales y Tesis SEA, vol. 1. Zaragoza.

Navarrete A, Vela G, López J, Rodríguez Ma. De L. Naturaleza y Utilidad de los Indicadores de Calidad del Suelo. Revista Contactos. 2011;80:29-37.

Rincón A, Caicedo S. (2010). Establecimiento de Pastos en Sistemas Ganaderos de los Llanos Colombianos. En Rincón, A. \& Jaramillo, C. A. (Eds). Establecimiento, Manejo y Utilización de Recursos Forrajeros en Sistemas Ganaderos de Suelos Ácidos (pp. 75-80). Villavicencio: Produmedios.

Rincón A. (1999). Degradación y recuperación de praderas en los llanos orientales de Colombia. Boletín técnico No. 19. CORPOICA-PRONATA.

Rincón A. (2010). Degradación de Praderas y Estrategias para su Recuperación. En Rincón, A. \& Jaramillo, C. A. (Ed/s). Establecimiento, Manejo y Utilización de Recursos Forrajeros en Sistemas Ganaderos de Suelos Ácidos (pp. 152-171). Villavicencio: Produmedios.

Rodríguez NS, Lavelle P, Pulido X, Gutiérrez A, Bernal JH, Argüello O, Botero C, et al. (2013). Construcción de indicadores de ecoeficiencia para la altillanura plana en los municipios de

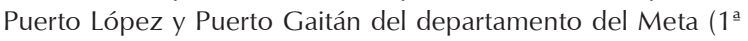
ed). Villavicencio: Produmedios.

Roncallo FB, Murillo SJ, Bonilla BR, Barros HJ. Evolución de las propiedades del suelo en un arreglo agrosilvopastoril basado en Ceiba roja (Pachira quinata (Jacq.) W.S. Alverson). CORPOICA Ciencia y Tecnología Agropecuaria. 2012;13(2): 167-178. 
Salamanca CR, Cano CA. (2005). "Efecto de las micorrizas y el sustrato en el crecimiento vegetativo y nutrición de cuatro especies frutales y una forestal, en la fase de vivero, en el municipio de Restrepo-Meta, Colombia" [conferencia], Encuentro Nacional de la Ciencia del suelo: 'Materia orgánica y microorganismos en la agricultura colombiana`, Medellín.

Salazar A. (2012). Crecimiento y rendimiento en Bosque Natural en C.I La Libertad. Universidad del Tolima. Trabajo no publicado

Schenk NC, Perez Y. (1990). Manual for the identification of mycorrhizal fungi $\left(3^{\underline{a}}\right.$ ed). University of Florida.
Sieverding E, Sánchez de PM, Bravo N. (1989). Investigaciones sobre micorrizas en Colombia. CIAT-Universidad Nacional. Palmira, Colombia.

Socarrás A, Robaina N. Caracterización de la mesofauna edáfica bajo diferentes usos de la tierra en suelo Ferralítico Rojo de Mayabeque y Artemisa. Pastos y Forrajes. 2011;34(2):185-198.

Velásquez E, Lavelle P, Andrade M. GISQ, a Multifunctional Indicator of Soil Quality. Soil Biol Biochem. 2007;39:3066-3080. 